\title{
Membrane-Assisted Condenser
}

\author{
Enrico Drioli ${ }^{1,2}$ (D) and Francesca Macedonio ${ }^{1,2, * \text { (D) }}$ \\ 1 Institute on Membrane Technology (ITM-CNR), c/o University of Calabria, 87036 Rende, Italy; \\ e.drioli@itm.cnr.it \\ 2 Department of Environmental and Chemical Engineering, University of Calabria, 87036 Rende, Italy \\ * Correspondence: francesca.macedonio@unical.it or f.macedonio@itm.cnr.it
}

Received: 5 March 2018; Accepted: 20 April 2018; Published: 25 April 2018

\begin{abstract}
In industrial processes, recycling and reusing of process streams-and of water, in particular-is necessary for minimizing fresh water requirements. Water supply issues are increasing in importance for new and existing industrial plants because the freshwater supply is limited and the forecast are that by 2025 two-thirds of people will live in regions with water scarcity. In this short note, the potentialities of a membrane-assisted condenser for the recovery of evaporated waste water from industrial gases are presented. The modelling of the process was carried out for predicting the membrane-based process performance. The experimental data were compared with the results achieved through the simulations. The comparison showed good agreement confirming the validity of the realized model and its suitability for a screening of the operative conditions to be utilized.
\end{abstract}

Keywords: membrane condenser (MC); water recovery; water composition

\section{Introduction}

Membrane engineering can have an interesting role in the innovation of process engineering trying to satisfy the requirements of a process intensification strategy [1,2]. The dominant role of integrated membrane based processes in desalination and industrial water treatment (reverse osmosis (RO), ultrafiltration (UF), nanofiltration (NF), microfiltration (MF)) [3,4], of membrane bioreactor (MBR) in the treatment of municipal wastewater, of various membrane systems in biomedical applications and in artificial organs [5], of hydrophobic microporous membranes in technical textiles, are some interesting examples of successful membrane operations. However, much more can be done! The design of basic unit operations of process engineering based on membranes is becoming a reality, as in the case of membrane distillation (MD), of membrane-assisted crystallization (MCr), of membrane emulsifiers, etc. [2]. One more interesting case is the membrane-assisted condenser [6-10]. It is important to notice that all the innovative membrane-assisted operations not only satisfy the process intensification strategy, but they also introduce new important properties not existing in the traditional existing unit operations. This is the case with specific polymorph crystallization in $\mathrm{MCr}[11,12]$, of production of monodisperse nanoparticles in the membrane emulsification [13], of the use of waste heat and/or solar energy in MD [14,15], etc.

In the present manuscript, membrane-assisted condenser is briefly described. In particular, the potentialities of the process as well as some results of the modeling and of the experiments will be shown.

\section{Description of the Technology}

A membrane condenser (MC) is an innovative membrane technology that exploits the hydrophobic nature of microporous membranes to promote water vapor condensation and recovery. 
What the MC does is separate water molecules from the other molecules present in the gas stream. In detail, a MC feed is a gaseous stream, at a certain temperature and, in most of the cases, water saturated. It is introduced to the MC module whose temperature is equal or lower than the one of the feed. In the membrane module, hydrophobic membranes are utilized to recover the liquid water at the feed side whereas the more or less dehydrated gases pass through the membrane and are removed at the permeate side of the unit (Figure 1).

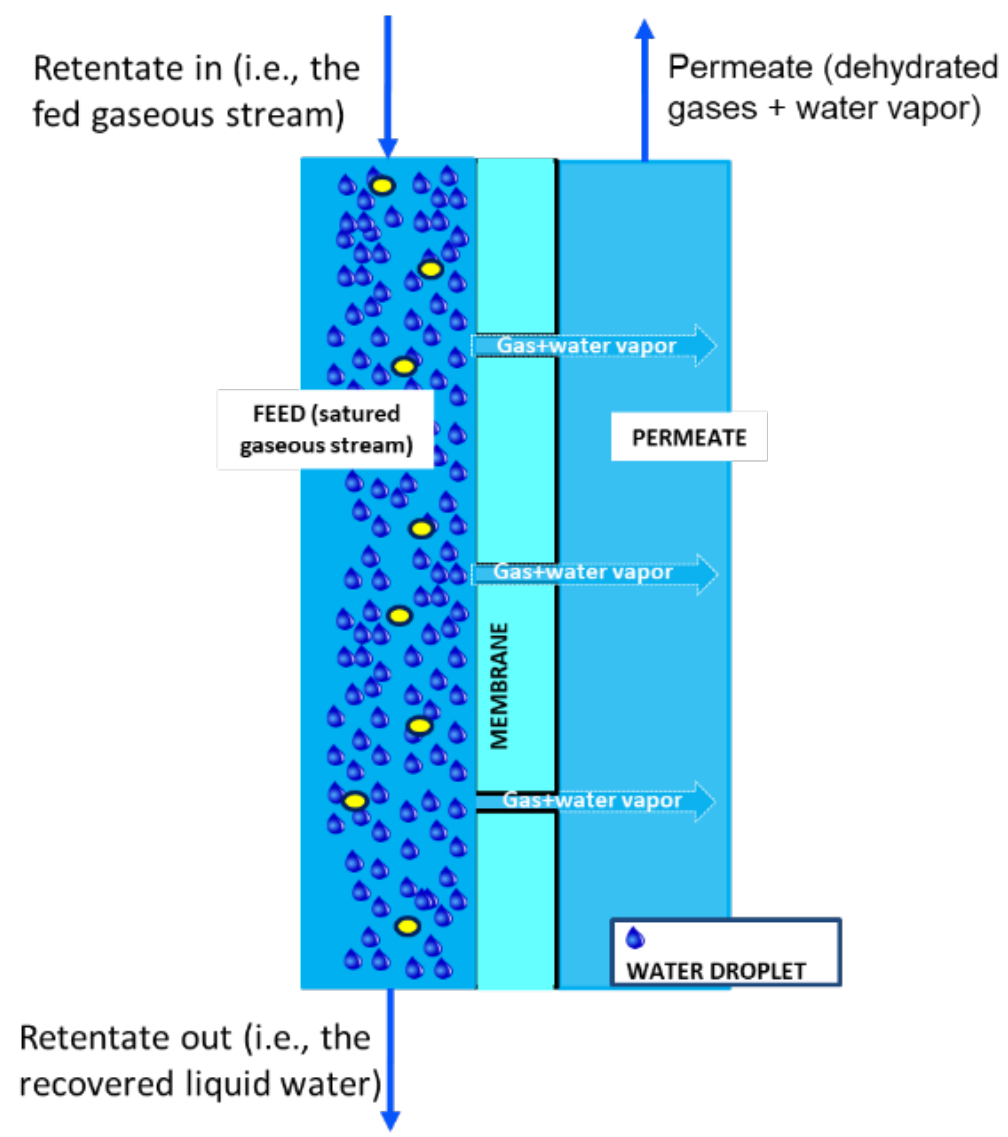

Figure 1. Basic principle of membrane condenser (MC).

The main traditional technologies for the capture of evaporated water by gaseous streams are cooling with condensation [16], liquid and solid sorption [17], and dense membranes or porous hydrophilic membranes [18]. Each of them has their own advantages and disadvantages:

- traditional condensers represent the easiest process even if corrosion phenomena due to the presence of acid pollutant in the waste gases stream are their main limitation;

- $\quad$ adsorption of water by a liquid or solid desiccant is another valid alternative despite desiccant losses, cost and regeneration of adsorbent, and low quality of water are the main drawbacks;

- $\quad$ high energy consumption due to the high pressure requirements is associated with the utilization of dense membrane for the recovery of water vapor from the gaseous streams.

With respect to the aforementioned technologies, MC advantages are:

- $\quad$ no corrosion phenomena because membrane can be fabricated from almost any chemically resistant polymers with hydrophobic intrinsic properties;

- energy consumption of a MC is lower with respect to that of either cryogenic separation or dense membrane, due to the high difference in boiling point between the gases and water in the first process and due to the high pressure requirements in the second process; 
- with respect to liquid or solid sorption, a MC is not effected by problems such as desiccant losses, cost and regeneration of adsorbent, and low quality of the produced water.

\section{Methods}

As a general description, MCs represent a special category of membrane contactors where two streams are separated and/or put in contact by means of a membrane. Detailed relations and models for transport phenomena through the MC are outside the scope of this work and details can be found in cited literature [6,9] as different possible condenser designs [10]. Briefly, vapor flux $N$ across the membrane follows the reduced Knudsen-molecular diffusion transition form of the dusty-gas model (DGM). When $N$ is known, the amount of water that can be recovered from the fed gaseous stream can be calculated with the following equation

$$
\text { Fraction of recovered water }=\frac{\left[\mathrm{n}_{\mathrm{H}_{2} \mathrm{O}, \text { feed }}-\left(\frac{\mathrm{P}_{\mathrm{H}_{2} \mathrm{O}}\left(\mathrm{T}_{\text {out }}\right) \cdot\left(\mathrm{n}_{\text {feed }}-\mathrm{n}_{\mathrm{H}_{2} \mathrm{O} \text {,feed }}\right)}{\mathrm{P}-\mathrm{P}_{\mathrm{H}_{2} \mathrm{O}}\left(\mathrm{T}_{\text {out }}\right)}-\mathrm{N} \cdot \mathrm{a}\right)\right]}{\mathrm{n}_{\mathrm{H}_{2} \mathrm{O} \text {,feed }}}
$$

where $\mathrm{n}_{\mathrm{H}_{2} \mathrm{O} \text {,feed }}$ is the number of water moles in the fed gaseous stream, $\mathrm{n}_{\text {feed }}$ is the total number of fed gaseous moles, $\mathrm{P}_{\mathrm{H}_{2} \mathrm{O}}\left(\mathrm{T}_{\text {out }}\right)$ is the partial pressure of water at the temperature at the exit of the condenser $\left(\mathrm{T}_{\text {out }}\right)$, and $\mathrm{a}$ is the membrane area.

MC modeling enabled the prediction of process performance in terms of quantity and quality of the recovered water and energy consumption. It was found that water recovery increases either growing $\Delta \mathrm{T}$ (temperature difference between the waste gaseous stream and the membrane module), or $\mathrm{RH}^{\text {Feed }}$ (relative humidity of the waste gaseous stream), or $\mathrm{T}^{\text {Feed }}$ (temperature of the waste gaseous stream). One more parameter most influencing the process is ratio between the feed flow rate $Q_{\text {Feed }}$ and interfacial membrane area $\mathrm{A}_{\text {Membrane }}$ : a low value of this ratio means that the membrane area is more than sufficient to treat the feed; on the contrary, a high value of the ratio implies that the feed flow rate is too high with respect to the membrane area available in the module; as a consequence, keeping the membrane area constant and increasing $Q_{\text {Feed, }}$, the amount of water recovered will increase not proportionally at the increasing $\mathrm{Q}_{\text {Feed }}$. The ratio $\mathrm{Q}_{\text {Feed }} / \mathrm{A}_{\text {Membrane }}$ affects also the concentration of the contaminants. Moreover, it was found that this happens only until when $Q_{\text {Feed }}$ is 1.52 times higher

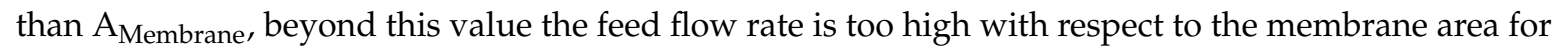
detaining more compounds and water concentration will not decrease further.

The results of the modeling were validated experimentally through tests performed on a MC prototype (whose description can be found elsewhere [6]).

In the following section, some of the most significant results obtained with the modeling and the comparison between modeling and experiments are described.

\section{Results}

As aforementioned, the simulation gives indications on the amount of recovered liquid water, on its composition and on the energy consumption of the process. For what concerns the condenser heat duty (i.e., the condenser energy consumption), the total power is due to the electrical power required to drive a fan or a blower, and to the heat duty required to cool the gaseous feed stream. Due to the low operating pressure of the process, the condenser heat duty is mainly due to the heat required to condense the water vapor (Figure 2). 


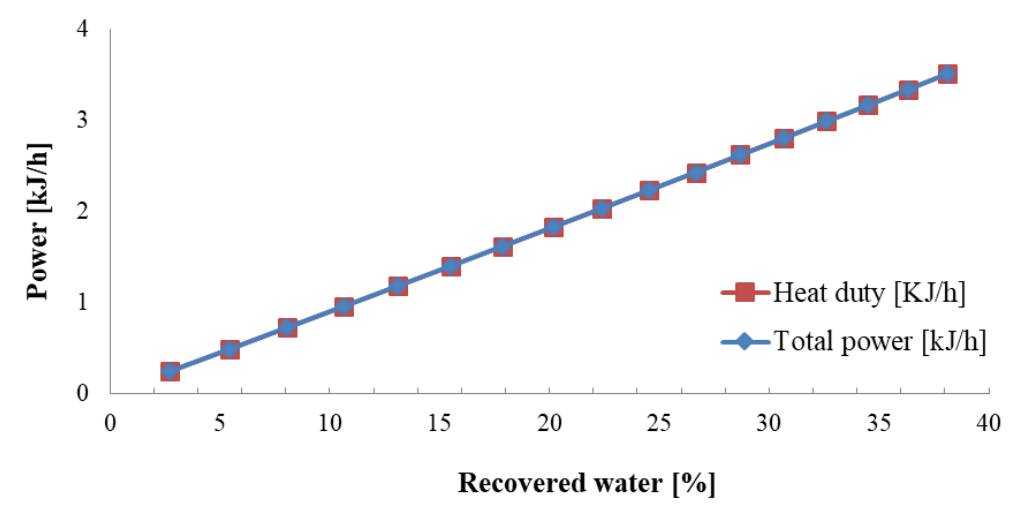

Figure 2. Theoretical estimation of the power needed to drive the process as a function of recovered water. Feed gas: $\mathrm{RH}=100 \%, \mathrm{~T}=55.5^{\circ} \mathrm{C}, \mathrm{Q}_{\text {Feed }}=452.2 \mathrm{~mL} / \mathrm{min}$.

The amount of recovered liquid water strongly depends on the temperature of the module and, as a consequence, on the temperature difference $(\Delta \mathrm{T})$ between the feed gas and membrane module. Figure 3 shows the results obtained for a gaseous stream at $55.5^{\circ} \mathrm{C}$ whose relative humidity (RH) is $100 \%$. It can be observed that around $30 \%$ of the water vapor contained in the feed can be recovered cooling the gaseous stream of around $6.5^{\circ} \mathrm{C}$ (i.e., $\mathrm{T}_{\text {module }}=49^{\circ} \mathrm{C}$ ).

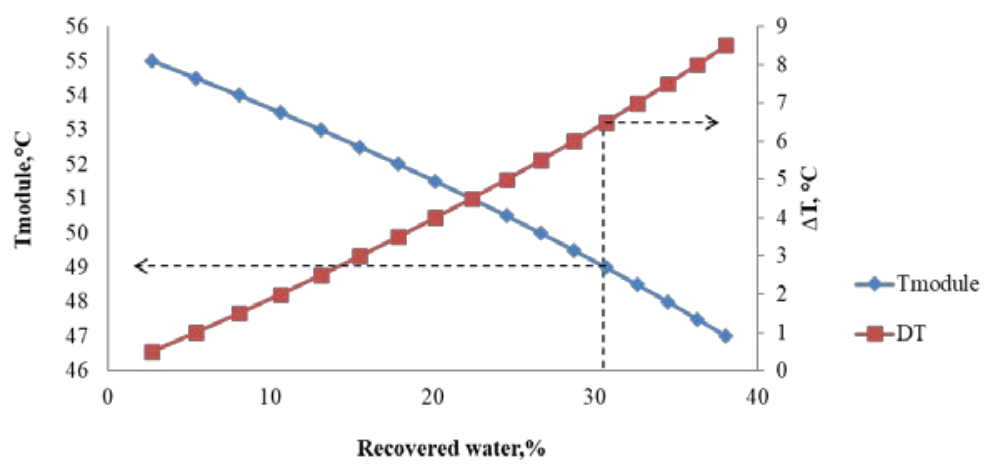

Figure 3. Theoretical estimation of the temperature of the membrane module and $\Delta \mathrm{T}$ (i.e., temperature reduction between the feed gas and membrane module) as a function of recovered water (Feed gas: $\left.\mathrm{RH}=100 \%, \mathrm{~T}=55.5^{\circ} \mathrm{C}, \mathrm{Q}^{\text {Feed }}=452.2 \mathrm{SCCM}\right)$.

One of the main advantages of a MC is the possibility to control the composition of the recovered liquid water. An example can be found in Figure 4 which shows the amount of $\mathrm{SO}_{\mathrm{x}}$ and $\mathrm{NH}_{3}$ in the recovered water. It can be observed that the concentration of these contaminants can be controlled modulating the cooling of the feed: the higher the cooling, the higher the concentration will be. Moreover, depending on the solubility behavior of the considered component (i.e., on its Henry's law constant), the cooling effect is different for the various contaminants: components such as $\mathrm{SO}_{\mathrm{x}}$, whose Henry's law constant has a low dependence on temperature are less sensitive to cooling with respect to component such as $\mathrm{NH}_{3}$ (characterized by an higher dependence on temperature). The composition of the recovered water as well as its amount can be further controlled acting on the feed flow rate $\mathrm{Q}_{\text {Feed }}$. As shown in Figure 5, $\mathrm{SO}_{\mathrm{x}}$ concentration and the amount of recovered water reduces increasing feed flow rate. This trend has to be attributed to the fact that the high $\mathrm{Q}_{\mathrm{Feed}}$ with respect to the membrane area available in the module did not allow to efficiently detain the contaminants. Figure 5 also reports the good agreement between experimental tests and model. This confirms the validity of the simulation study done and its suitability for predicting MC performance. 


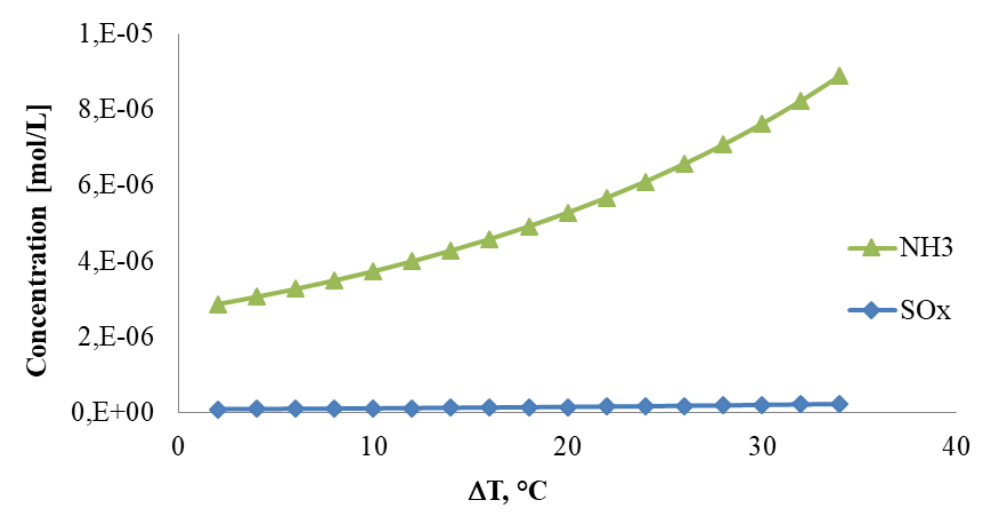

Figure 4. Theoretical estimation of $\mathrm{NH}_{3}$ and $\mathrm{SO}_{x}$ concentration in the recovered water as a function of $\Delta \mathrm{T}$. Feed gas: $\mathrm{RH}=100 \%, \mathrm{~T}=90^{\circ} \mathrm{C}, \mathrm{Q}_{\text {Feed }}=452.2 \mathrm{SCCM}, \mathrm{NH}_{3}=150 \mathrm{vppm}, \mathrm{SO}_{\mathrm{x}}=150 \mathrm{vppm}$.

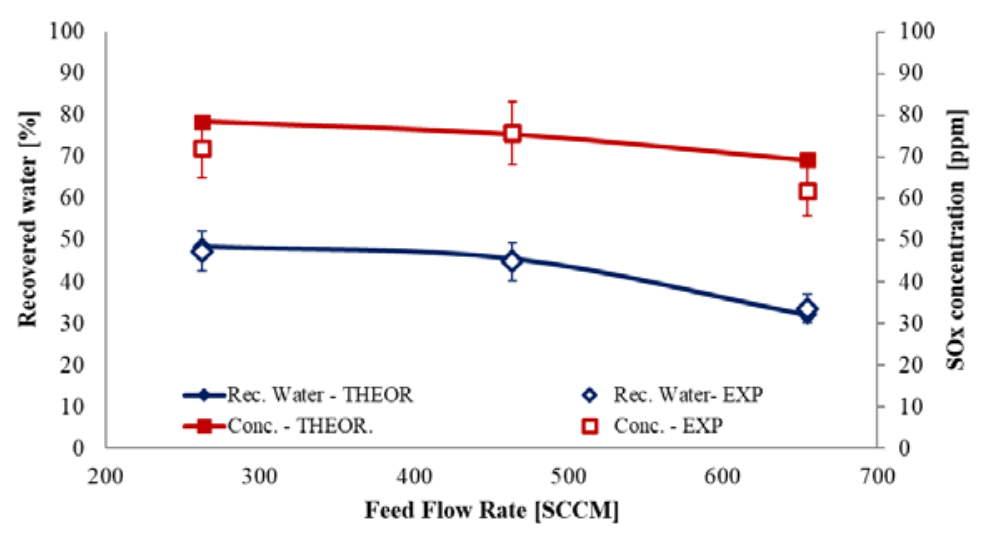

Figure 5. Recovered water and concentration vs. $\mathrm{Q}^{\text {Feed }}$. Symbols: experimental results; lines: simulation results. Feed temperature $=54.8-55.6{ }^{\circ} \mathrm{C}, \mathrm{RH}$ feed $=100 \%, \Delta \mathrm{T}=13.3-18.8^{\circ} \mathrm{C}$.

The potentiality of this membrane-assisted condenser can be of particular interest as general pretreatment to the gas separation membrane system as the case of $\mathrm{H}_{2}$ purification, $\mathrm{CO}_{2}$ capture, etc. In gas separation, high level of humidity can have an influence on membrane life time, on their performances in terms of transmembrane flux and selectivity. The possibility to optimize RH in the gaseous streams and eventually the removal of specific contaminants might be realized using membrane-assisted condensers. Their role in gas separation systems in the pre-treatment stage might became dominant, as today MF, UF, and/or NF became fundamental pre-treatment to RO unit in desalination of seawater and brackish waters [2,3].

\section{Conclusions}

The MC is an innovative membrane unit operation for the selective recovery of evaporated waste water from industrial gases and for the control of the composition of the recovered liquid water. It has several advantages with respect to the technologies proposed to date for the capture of evaporated water from gaseous streams:

- $\quad$ it does not suffer corrosion phenomena of traditional condensers because membrane can be fabricated from almost any chemically resistant polymers with hydrophobic intrinsic properties; - $\quad$ it can control the concentration of contaminants in the recovered liquid water.

The carried out simulations enabled prediction of the membrane module performance in terms of energy consumption, and amount and composition of the recovered water. The achieved results indicate that the temperature difference $\Delta \mathrm{T}$ between the feed $\mathrm{T}_{\text {feed }}$ and the membrane module, and 
the ratio between the feed flow rate $Q_{F e e d}$ and interfacial membrane area $A_{\text {Membrane }}$ are fundamental parameters to be taken into account. The results of the modeling were validated experimentally via tests performed on a membrane condenser prototype. It was found that recovery factor as high as $44.8 \%$ with $\mathrm{SO}_{\mathrm{x}}$ concentration as low as $75.7 \mathrm{ppm}$ can be obtained from waste gaseous stream at $55.8^{\circ} \mathrm{C}$ and $\mathrm{RH}=100 \%$.

Author Contributions: Francesca Macedonio performed the work and wrote the manuscript. Enrico Drioli supervised the work and revised the manuscript.

Conflicts of Interest: The authors declare no conflict of interest.

\section{References}

1. Drioli, E.; Stankiewicz, A.I.; Macedonio, F. Membrane Engineering in Process Intensification-An Overview. J. Membr. Sci. 2011, 380, 1-8. [CrossRef]

2. Macedonio, F;; Drioli, E. Membrane Engineering for Green Process Engineering. Engineering 2017, 3, 290-298. [CrossRef]

3. Drioli, E.; Criscuoli, A.; Macedonio, F. Membrane-Based Desalination: An Integrated Approach; IWA Publishig: London, UK, 2011.

4. Macedonio, F.; Drioli, E. Chapter 6. Advanced membrane based desalination systems for water and minerals extraction from the sea. In Desalination Sustainability: A Technical, Socioeconomic, and Environmental Approach; Arafat, H., Ed.; Elsevier: New York, NY, USA, 2017; pp. 237-259.

5. De Bartolo, L.; Curcio, E.; Drioli, E. Membrane Systems: For Bioartificial Organs and Regenerative Medicine; Walter de Gruyter GmbH \& Co KG: Berlin, Germany, 2017.

6. Macedonio, F.; Brunetti, A.; Barbieri, G.; Drioli, E. Membrane Condenser as a new technology for water recovery from humidified "waste" gaseous streams. Ind. Eng. Chem. Res. 2013, 52, 1160-1167. [CrossRef]

7. Drioli, E.; Santoro, S.; Simone, S.; Barbieri, G.; Brunetti, A.; Macedonio, F.; Figoli, A. ECTFE membrane preparation for recovery of humidified gas streams using membrane condenser. React. Funct. Polym. 2014, 79, 1-7. [CrossRef]

8. Brunetti, A.; Santoro, S.; Macedonio, F.; Figoli, A.; Drioli, E.; Barbieri, G. Waste gaseous streams: From environmental issue to source of water by using membrane condensers. CLEAN Soil Air Water 2014, 42, 1145-1153. [CrossRef]

9. Macedonio, F.; Cersosimo, M.; Brunetti, A.; Barbieri, G.; Drioli, E. Water Recovery from Humidified Waste Gas Streams: Quality Control Using Membrane Condenser Technology. Chem. Eng. Process. Process Intensif. 2014, 86, 196-203. [CrossRef]

10. Macedonio, F.; Brunetti, A.; Barbieri, G.; Drioli, E. Membrane condenser configurations for water recovery from waste gases. Sep. Purif. Technol. 2017, 181, 60-68. [CrossRef]

11. Quist-Jensen, C.A.; Macedonio, F.; Horbez, D.; Drioli, E. Reclamation of sodium sulfate from industrial wastewater by using membrane distillation and membrane crystallization. Desalination 2017, 401, 112-119. [CrossRef]

12. Di Profio, G.; Tucci, S.; Curcio, E.; Drioli, E. Selective glycine polymorph crystallization by using microporous membranes. Cryst. Growth Des. 2017, 7, 526-530. [CrossRef]

13. Yanagishita, T.; Tomabechi, Y.; Nishio, K.; Masuda, $\mathrm{H}$. Preparation of monodisperse $\mathrm{SiO}_{2}$ nanoparticles by membrane emulsification using ideally ordered anodic porous alumina. Langmuir 2004, 20, 554-555. [CrossRef] [PubMed]

14. Banat, F.; Jumah, R.; Garaibeh, M. Exploitation of solar energy collected by solar stills for desalination by membrane distillation. Renew. Energy 2002, 25, 293-305. [CrossRef]

15. Shim, W.G.; He, K.; Gray, S.; Moon, I.S. Solar energy assisted direct contact membrane distillation (DCMD) process for seawater desalination. Sep. Purif. Technol. 2015, 143, 94-104. [CrossRef] 
16. Michels, B.; Adamczyk, F.; Koch, J. Retrofit of a Flue Gas Heat Recovery System at the Mehrum Power Plant. An Example of Power Plant Lifetime Evaluation in Practice. In Proceedings of the POWER-GEN Europe Conference 2004, Barcelona, Spain, 25-27 May 2004; pp. 10-11.

17. Folkedahl, B.; Weber, G.F.; Collings, M.E. Water Extraction from Coal-Fired Power Plant Flue Gas; Final Report, DOE Cooperative Agreement No. DE-FC26-03NT41907; National Energy Technology Laboratory: Pittsburgh, PA, USA, 2006.

18. Scovazzo, P.; Hoehn, A.; Todd, P. Membrane Porosity and Hydrophilic Membrane-Based Dehumidification Performance. J. Membr. Sci. 2000, 167, 217-225. [CrossRef]

2018 by the authors. Licensee MDPI, Basel, Switzerland. This article is an open access article distributed under the terms and conditions of the Creative Commons Attribution (CC BY) license (http:// creativecommons.org/licenses/by/4.0/). 